\section{ONOMAREDIN}

Revista semestral de lingüística, filología y traducción
PONTIFICIA UNIVERSIDAD CATÓLICA DE CHILE CATOLICA DE CHILE
FACULTAD DE LETRAS

\title{
Fraseología jurídica y variación topolectal
}

Juridical Phraseology and topolectal variation

\section{Encarnación Tabares Plasencia}

Universität Leipzig

Alemania

\section{(c) $($ i) $\ominus$}

Encarnación Tabares: Institut für Angeawandte Linguistik und Translatologie, Philologische Fakultät, Universität Leipzig, Alemania. | Correo electrónico: tabares@server1.rz.uni-leipzig.de 


\section{Resumen}

La variación en el campo de la fraseología ha sido objeto de numerosos estudios en el ámbito de la lengua general. En cuanto a la fraseología de los textos especializados, ya, desde finales de los años noventa del siglo XX, ha habido voces que se han alzado para destacar la relevancia de atender a la variación fraseológica en los textos especializados en muchos ámbitos, entre ellos, el de la traducción especializada.

En este trabajo se tratará la variación fraseológica jurídica desde el punto de vista topolectal en un corpus de sentencias de materia penal hispánicas.
Para ello, en primer lugar, se aplicará a dicho corpus, para su validación, el modelo de clasificación de UFED (Unidades Fraseológicas del Derecho) de Tabares Plasencia (2012) y, en segundo lugar, se ofrecerá una muestra de la variación en los textos analizados, como primer paso para su sistematización con el fin de elaborar una base de datos de UFED de este género textual - ampliable a otros en el futuro- dirigida a traductores en la combinación lingüística alemán y español.

Palabras clave: variación topolectal; fraseología; traducción; textos especializados; UFED.

\section{Abstract}

Variation in the field of phraseology has been the object of numerous studies of the common language. Since the last decade of the 2oth century several investigations stressed the relevance of the phraseological variation in texts for special purposes in many fields, as for instance for specialized translation.

In this paper the phraseological variation in legal texts is treated from a topolectal point of view in a cor- pus consisting of sentences from Hispanic penal law. Firstly, the corpus is analyzed using the model introduced by Tabares Plasencia (2012). Secondly, a sample of variation in the analyzed texts is proposed in order to systematize this variation and to develop a database of PLU (Phraseological Legal Units) for this type of texts, applicable to other text types in the future, which is addressed to Spanish-German translators.

Keywords: topolectal variation; phraselogy; translation; specialized texts; UFED. 


\section{Introducción. Fraseología especiali- zada y variación}

Es bien sabido que la variación fraseológica ha sido objeto de numerosos trabajos en el ámbito de la lengua general. Son clásicos los estudios de Zuluaga (1980), Dobrovol'skij (1988) y de Corpas (1996), donde se le dedica un importante espacio a esta cuestión. Más específicamente, se ocupan de la variación en la fraseología de la lengua general, entre otros, los de García-Page (1996 y 1999), Koike (2001 y 2003), Montoro del Arco (2004) y Ortega y González Aguilar (2005).

En el campo de la fraseología especializada, desde fines de los años noventa del pasado siglo, los miembros del grupo de investigación IULATerm de la Universidad Pompeu Fabra de BarceIona trabajaban sobre este aspecto de los textos especializados y en el año 1999 Tercedor señalaba "la importancia de dar cuenta de la variación fraseológica en los textos de contenido especializado". Pero, como ya ha señalado Cabré (2005), todos los estudiosos reconocen la existencia de una fraseología propia de cada especialidad, pero ni los diccionarios especializados suelen recogerla, ni las gramáticas de las lenguas de especialidad acostumbran a tratarla.

Además, la falta de precisión acerca de los que deben considerarse fenómenos propia- mente fraseológicos (Cabré, Estopà y Lorente, 1996) no ha ayudado demasiado a profundizar en la cuestión. En un trabajo anterior (Tabares Plasencia, 2012), por mencionar uno de los más recientes, ya se ponía de manifiesto la falta de consenso a la hora de ofrecer una taxonomía o clasificación de las UFE (Unidades Fraseológicas Especializadas). Así, se aislaban como fraseológicas un tipo de unidades u otro, dependiendo del enfoque que se adoptara (lexicográfico, terminológico o traductológico, fundamentalmente) (Tabares Plasencia, 2012: 316-318; Bevilacqua, 2004: 25-33). Teniendo en cuenta que esta es la situación para la fraseología especializada en general, para la fraseología jurídica específicamente no es mucho mejor, a pesar de que se han hecho algunos intentos como en Pastor Lara y Tabares Plasencia (2012).

\section{La fraseología jurídica}

Desde los años noventa, Kjaer (1991, 1994 y 2007) ha sido de las pocas en explorar sistemáticamente el ámbito de la fraseología jurídica, desde la perspectiva aplicada y traductológica - que es la que aquí me interesa-, aunque en la combinación lingüística alemán-danés. En 2007 nos presenta su clasificación, que puede verse en el cuadro $I^{1}$.

\section{CUADRO 1}

Categorías fraseológicas de Kjaer (2007)

\begin{tabular}{|c|c|}
\hline CATEGORİAS & EJEMPLOS \\
\hline Términos poliléxicos (multi-word-terms) & $\begin{array}{l}\text { patria potestad, represesentante legal, buenas } \\
\text { costumbres, medida cautelar, etc. }\end{array}$ \\
\hline Colocaciones (collocations) & $\begin{array}{l}\text { otorgar testamento, concluir un contrato, dictar } \\
\text { sentencia, etc. }\end{array}$ \\
\hline $\begin{array}{l}\text { Construcciones con verbo soporte } \\
\left.\text { (Funktionsverbgefüge }^{2}\right)\end{array}$ & $\begin{array}{l}\text { entrar en vigor, incurrir en mora, imponer una } \\
\text { pena, etc. }\end{array}$ \\
\hline Binomios fraseológicos (binomials) & daños y perjuicios, cargas y gravámenes, etc. \\
\hline $\begin{array}{l}\text { Frasemas con componentes únicos (legal } \\
\text { phrasemes with arcaic forms) }\end{array}$ & de oficio, ad solemnitatem, etc. \\
\hline
\end{tabular}

1 He traducido al español tanto las categorías clasificatorias como los ejemplos ofrecidos por la autora del estudio, originalmente escrito en inglés, pero con ejemplos fundamentalmente del Derecho alemán, en lengua alemana.

2 En alemán, en el original inglés 
En la combinación lingüística alemán-español, por el contrario, no había trabajos abarcadores de todos los fenómenos fraseológicos que podrían encontrarse en los textos jurídicos con relevancia para la traducción. Por eso, en 2012 ofrecí mi propuesta de caracterización y clasificación de las que he dado en Ilamar UFED (Unidades Fraseológicas Especializadas del Derecho) en castellano o PER (Phraseologische Einheiten des Rechts) en alemán³.

Con anterioridad, merecen destacarse los trabajos llevados a cabo por García Valle (2006, 2008 y 2010, por ejemplo) y García Valle y Ricós Vidal (2007) dentro del proyecto de investigación FRASLEDIA (Fraseología de la lengua castellana en su diacronía: desde los orígenes hasta el siglo $X V I I I)^{4}$. Estas autoras, que realizan un tratamiento lingüístico y filológico de las unidades fraseológicas en documentos medievales, aplican a estas la terminología y las propiedades que se han predicado de los fraseologismos en estudios que analizan sin propósitos específicos. Así, en García Valle (2010: 138), puede leerse:

$Y$, por lo que se refiere a las locuciones, consideradas como un subtipo dentro de las unidades fraseológicas, compartimos las opiniones de Casares, Zuluaga, Corpas, Ruiz Gurillo, Penadés, etc., recogidas ahora por Montoro del Arco, al señalar que se caracterizan por la función autónoma que cumplen en el interior del enunciado, y, además, por "ser pluriverbales y tener algún grado de fijación, variación potencial fija y especialización semántica, esto es, idiomaticidad".

En Tabares Plasencia (2012: 314-315), a donde remito para una explicación detallada, se indica la incoveniencia de asumir sin reservas los planteamientos de la Fraseología de la lengua general para describir las unidades fraseológicas jurídicas. Sobre todo, resulta muy polémico el concepto de idiomaticidad. Por lo demás, las UFED presentan ciertas características no atribuibles o no atribuibles de la misma manera a las unidades no especializadas.

En las publicaciones de García Valle (2006, 2008, 2010) y García Valle y Ricós Vidal (2007) no se examinan de forma sistemática los fraseologismos en los textos medievales. Solo se destacan las fórmulas jurídicas y las locuciones adverbiales, en términos de las investigadoras; no se han trabajado otras unidades que son básicas en los textos especializados jurídicos, esto es, las construcciones verbonominales (Tabares Plasencia, 2012: 323-324) o colocaciones. Además, aunque tanto en García Valle (2010, por ejemplo) como en García Valle y Ricós Vidal (2007) se tiene en cuenta el fenómeno de la variación, lo cierto es que no se establece una distinción clara entre variación y variantes, que parece emplearse, en muchos casos, como forma sinonímica (véase

3 En otras combinaciones lingüísticas se han realizado algunos estudios de interés. Remito a los trabajos surgidos dentro del proyecto Termisul, dirigido por Maria da Graça Krieger, que, desde los años noventa, viene trabajando sobre la fraseología del dominio del Derecho Medioambiental y en el que destaca, entre otros, Cleci Bevilacqua (véanse Bevilacqua, 1996a y 1996b; Feldekircher y Bevilacqua, 2010). En la actualidad, y también en el marco de Termisul, se está desarroIlando un subproyecto dedicado a la elaboración de una base de datos de fraseología legal (Derecho Medioambiental), Combinatórias Léxicas Especializadas da Linguagem Legal.

4 En 2003, Echenique Elizondo, la directora de este proyecto, publicó un trabajo donde establecía los parámetros de análisis de los fraseologismos castellanos adoptando un enfoque diacrónico. La autora aceptaba de manera expresa el concepto de unidad fraseológica de Corpas Pastor (1996) (Echenique Elizondo, 2003: 545) y consideraba que, para hacer un estudio de su estructura, es necesario, en primer lugar, elaborar un corpus que permita, posteriormente, realizar adecuadamente su estudio lingüistico. Asimismo, indicaba que han de tenerse en cuenta aspectos como el papel de los universales lingüísticos en fraseología, la oralidad frente a la escritura, la fuerza ilocucionaria (o función comunicativa), la fijación, que, según la investigadora, se ha dado por la repetición reiterada a lo largo de la historia de la lengua, los problemas de homonimia, polisemia, sinonimia o antinomia, la motivación en los fraseologismos idiomáticos, etc. (Echenique Elizondo, 2003: 547 y ss.).

5 La falta de diferenciación resulta, cuando menos, curiosa si tenemos en cuenta que autores como los que citábamos al principio de la Introducción, esto es, Zuluaga (1980), Corpas (1996), García-Page (1996 y 1999), Koike (2001 y 2003), Montoro del Arco (2004) y Ortega y González Aguilar (2005) han dedicado numerosas páginas a intentar establecer una clara frontera entre los conceptos de variante y variación. 
García Valle, 2010: 141, 142, 145, 149, 154, 157, etc., y García Valle y Ricós Vidal, 2007: 173, 174, 175, etc.).

Por todo ello, y a pesar del mérito que supone trabajar con textos de gran complejidad lingüística y de difícil acceso, no creo que el enfoque de estas autoras sea el más afortunado para una investigación como la que se realiza en este caso. De hecho, en el trabajo de Tabares Plasencia (2012) antes mencionado, se señalaba que la perspectiva terminológica se había revelado como una de las más fecundas para abordar la fraseología de los lenguajes con fines específicos desde los años ochenta del siglo XX, hecho que ya había puesto de manifiesto explícitamente Kjaer al hablar de "dominance of the terminological point of view" (2007: 506-507) y otros autores que habían asumido este enfoque para abordar el fenómeno fraseológico en los textos especializados (en este mismo sentido, véase Gläser, 2007). Así, tomando como base la propuesta de Gouadec (1994), según la cual los atributos esenciales de las UFE (Unidades Fraseológicas Especializadas) serían la estereotipicidad y su especificidad en un determinado dominio y asumiendo su concepto de matriz fraseológica, se estableció una definición y clasificación propias de las UFED. En cuanto a la definición, una UFED es una cadena de palabras que, normalmente, aunque no indispensablemente, contiene al menos un término (simple o poliléxico) y presenta un grado de fijación, convención y usualización que la hacen prototípica y específica, esto es, reconocible como unidad de conocimiento especializado ${ }^{6}$ en los distintos géneros textuales del discurso jurídico (Tabares Plasencia, 2012: 321). Estas unidades de conocimiento especializado resultan obvias para los expertos en Derecho y constituyen un elemento necesario para entender y producir textos jurídicos adecuados y válidos en una lengua y un sistema jurídico determinados.

De la definición consignada se extraen una serie de propiedades tanto de orden interno como externo que permiten el reconocimiento de las UFED. Entre las propiedades de orden interno o lingüístico podrían mencionarse:

a) Ia coaparición más o menos reiterada de, como mínimo, dos elementos lingüísticos de los que uno suele ser un término (ya sea monoléxico, ya sea poliléxico);

b) una relativa fijación que produce cierto grado de lexicalización, sin que ello impida transformaciones (nominalización, pasivización, pronominalización, etc.) ni variaciones?.

Atendiendo ahora a las propiedades de orden externo o discursivo, destacan otras dos:

c) la institucionalización dentro del discurso jurídico, esto es, su convencionalización en los distintos géneros textuales del discurso del Derecho, lo que determina que, prima facie, las UFED únicamente sean detectables por los expertos en Derecho (véase Kjaer, 1991, 1994, 2007) y que la frecuencia de coa-

6 Término propuesto por Cabré (2002)

7 Por ejemplo, en la unidad contraer matrimonio tratada en textos legales españoles (véanse Tabares Plasencia y Pérez Vigaray, 2017: 572-573;Tabares Plasencia, 2010: 287), se constataban las siguientes transformaciones: Transformaciones sintácticas: a) pronominalización: "El Juez, Alcalde o funcionario, después de leídos los artículos 66, 67 y 68 preguntará a cada uno de los contrayentes si consienten en contraer matrimonio con el otro y si efectivamente lo contraen en dicho acto" (art. 58 del Código Civil español, en adelante CC); pasivización, mediante el uso del se: "Es nulo, cualquiera que sea la forma de su celebración: [...] 3. El que se contraiga sin la intervención del Juez, Alcalde o funcionario ante quien deba celebrarse” (art. 73 CC) y relativización: “Es nulo, cualquiera que sea la forma de su celebración: (...) 3. El que se contraiga sin la intervención del Juez, Alcalde o funcionario ante quien deba celebrarse" (art. 73 CC); Transformaciones paradigmáticas (variaciones categoriales del núcleo verbal de la construcción); adjetivación: como participio pasado, contraído (de matrimonio contraído): "Es nulo, cualquiera que sea la forma de su celebración: 5. El contraído por coacción o miedo grave" (art. 73 CC), como participio de presente (nombre de agente), contrayente: "El matrimonio tendrá los mismos requisitos y efectos cuando ambos contrayentes sean del mismo o de diferente sexo" (art. 44 CC); nominalización: en el texto legal analizado no se documentaban formas como *contracción o contraímiento de (I) matrimonio/matrimonial. 
parición de sus componentes no sea un criterio absolutamente determinante y, por último,

d) debido a esa institucionalización, y a pesar de que la fijación no sea absoluta, han de emplearse en ocasiones determinadas fórmulas fijas para lograr el efecto jurídico deseado, dado el carácter ritual que todavía sigue manteniendo el Derecho actual por influencia del romano.

La clasificación de las UFED que se propone está compuesta de tres categorías, siendo que dos de ellas se encontrarían en el nivel suboracional y la tercera en el nivel oracional y supraoracional, dependiendo de su composición:

1) Cadenas gramaticales con valor preposicional y fórmulas adverbiales del tipo que aparece en el cuadro 2.
Este grupo está integrado por unidades suboracionales que, o bien funcionan como grupos preposicionales con elementos variables que se completan contextualmente (muchas veces, con términos), o bien son fragmentos formularios que se repiten de forma estable sin que, en la mayor parte de los casos, se admitan variables. Se han incluido estas unidades por su relevancia para la producción y traducción de textos jurídicos.

2) Construcciones verbonominales, que son las UFED centrales y más importantes, por cuanto son las que mayor conocimiento especializado suelen transmitir. Un rasgo característico de las mismas es la presencia de un término que puede funcionar como sujeto, objeto directo o complemento preposicional de un verbo, abarcando así tanto las

\section{CUADRO 2}

Cadenas gramaticales con valor preposicional y fórmulas adverbiales

\begin{tabular}{|c|c|}
\hline $\begin{array}{l}\text { CADENAS GRAMATICALES } \\
\text { CON VALOR PREPOSICIONAL }\end{array}$ & $\begin{array}{l}\text { a (los) efectos de, a favor de, con arreglo a, en virtud de, en nombre y representación } \\
\text { de, de conformidad con, en calidad de, con base a/con, a instancia de, actuando en } \\
\text { nombre de, etc. }\end{array}$ \\
\hline FÓRMULAS ADVERBIALES & $\begin{array}{l}\text { hechas las reservas y advertencias legales, a un solo efecto, a cuyo efecto, con ple- } \\
\text { nas facultades, en prueba de conformidad, en cumplimiento con, de cumplirlo bien } \\
\text { y fielmente, de pleno derecho, con renuncia a (su) fuero propio, a mi juicio, a un solo } \\
\text { efecto, en su propio nombre y derecho, con carácter privativo, del pleno dominio, } \\
\text { en juicio, salvo que expresamente se disponga lo contrario, según el Derecho vigen- } \\
\text { te, en los términos que establezca la ley, etc. }\end{array}$ \\
\hline
\end{tabular}

\section{CUADRO 3}

Construcciones verbonominales CONSTRUCCIONES
VERBONOMINALES estar $(x)$ sujeto al régimen económico matrimonial, otorgar escritura, formalizar el/ los pacto(s), revocar el/un poder, tener capacidad legal y legitimación, autorizar escritura, cumplir la obligación, estar al corriente en el pago, formalizar el préstamo, respetar las normas legales, librar carta de pago, liquidar el impuesto, presentar declaración para el pago del impuesto, actuar $(x)$ en nombre de, hacerse cargo ( $x$ ) de, demandar en juicio a $(x)$, reservarse el derecho de, reservarse la facultad de, contraer matrimonio, interponer un recurso, dictar sentencia, entrar en vigor, desestimar la demanda, contestar a la demanda, traer a colación, entrar en quiebra, etc. 
Ilamadas colocaciones por una buena parte de los fraseólogos, como las construcciones con verbo soporte. En el cuadro 3 se muestran algunos ejemplos.

3) Textos formularios que se mueven dentro del ámbito oracional o supraoracional, puesto que abarcan desde enunciados fraseológicos hasta marcos (macro)textuales. Los marcos (macro)textuales (formelhafte Texte; cf. Gülich y Krafft, 1998) están constituidos por expresiones marco (Rahmenausdrücke, en palabras de Gülich y Kraft, 1998) o matrices (según Gouadec, 1994), en las que pueden insertarse elementos variables, rellenarse con información específica o ambas cosas Lo vemos en los ejemplos que se muestran en el cuadro 4

\section{La variación en el ámbito de los tex- tos especializados}

El fenómeno de la variación en los textos especializados ha sido estudiado, sobre todo, desde el ámbito de la Terminología. Dos tendencias han sido bastante productivas específicamente en el campo de la variación terminológica. Desde un enfoque descriptivo y tomando como base la Lingüística, en concreto la Sociolingüística, la TST (Teoría Sociolingüística de la Terminología) reconoce la variación como fenómeno normal que afecta a los términos y estima que, como tal, ha de ser descrito. Faulstisch (1995, 1997, 1998, 2000, 2002), dentro de la corriente socioterminológica, ha presentado un modelo de análisis de la variación terminológica, partiendo de las premisas siguientes: a) los términos son signos que

\section{CUADRO 4}

Textos formularios: enunciados fraseológicos y marcos (macro)textuales

\begin{tabular}{|c|c|}
\hline $\begin{array}{l}\text { ENUNCIADOS } \\
\text { FRASEOLÓGICOS }\end{array}$ & $\begin{array}{l}\text {-Leo a los comparecientes (esta /la presente) escritura, previa su renuncia del dere- } \\
\text { cho a hacerlo por sí, que les advierto que tienen, y la aprueban y firman conmigo, el } \\
\text { Notario, que DOY FE de su contenido y de que va extendida en... } \\
\text {-Les identifico por sus documentos de identidad y tienen a mi juicio capacidad legal } \\
\text { y legitimación para otorgar la presente ESCRITURA DE COMPRAVENTA. } \\
\text {-Y en prueba de conformidad, ambas partes firman este documento por duplicado, } \\
\text { quedando un ejemplar en poder de cada una de las partes, en la fecha y lugar que } \\
\text { lo encabeza. }\end{array}$ \\
\hline $\begin{array}{l}\text { MARCOS (MACRO) } \\
\text { TEXTUALES }\end{array}$ & $\begin{array}{l}\text { DECLARAN } \\
\text { Que reúnen [X] para [celebrar] el presente contrato y, [Y], acuerdan formalizarlo } \\
\text { con arreglo a las siguientes: } \\
\text { CLÁUSULAS9 } \\
\text { La Sala [X] del Tribunal [Y] en... (sede del tribunal) formada por los IItmos. Sres. Ma- } \\
\text { gistradoS D./Dña... (nombres de los magistrados), ha pronunciado } \\
\text { EN NOMBRE DELREY } \\
\text { la Siguiente } \\
\text { SENTENCIA }\end{array}$ \\
\hline
\end{tabular}

8 En este sentido, puede establecerse cierto paralelismo con las cadenas gramaticales, pues unas pueden completarse, mientras que otras tienen un carácter más fijo. Los elementos variables son restringidos (el juez o la ley, por ejemplo), mientras que las informaciones específicas son menos predecibles, mucho más abiertas.

9 Ejemplo extraído de Krüger y Tabares (2008: 110-111) 
encuentran su funcionalidad en las lenguas de especialidad de acuerdo con la dinámica de las lenguas; b) son entidades variantes porque forman parte de situaciones comunicativas distintas; c) son unidades del léxico especializado que pasan por evoluciones y, por ello, deben ser analizados en el plano sincrónico y diacrónico de las lenguas (1998). La autora propone la existencia de tres tipos de variantes:

1. Concurrentes. Las variantes concurrentes serían de índole formal. Abarcarían a las variantes formales lingüísticas (fonológicas, morfológicas, sintácticas, léxicas y gráficas) y a las variantes formales de registro (geográficas, de discurso y temporales) que discurrirían por el plano horizontal, vertical y temporal de la lengua. Tanto unas como otras se corresponderían con alternativas de denominación para un mismo referente y se darían en un contexto determinado. Por lo demás, la división en estos dos grandes grupos no implicaría que no pudiera haber cruzamientos entre ellas ${ }^{10}$.

2. Coocurrentes. Las variantes coocurrentes serían aquellas que tienen dos o más formas denominativas para un mismo concepto. Darían lugar a lo que para ella es la sinonimia terminológica, es decir, dos o más términos con significados básicamente idénticos que pueden darse en un mismo texto sin que se produzcan cambios de contenido.

3. Competitivas. Las variantes competitivas serían aquellas que relacionarían préstamos o calcos terminológicos de otras lenguas con los términos vernáculos.

También, desde la TCT (Teoría Comunicativa de la Terminología) se han hecho interesantes aportaciones al fenómeno de la variación terminológica. Freixa (2002: 54-56) se centra en los cambios que se pueden constatar en las denomi- naciones de los términos (variación denominativa) y en sus nociones (variación conceptual).

La variación denominativa sería el fenómeno por el cual a una misma noción le corresponderían varias denominaciones y vendría a ser lo que normalmente otros autores Ilaman sinonimia terminológica. La variación conceptual consistiría en los cambios en un mismo concepto. La autora emplea, además, el término variación denominativa para evitar la dificultad que existe a la hora de distinguir entre sinónimos y variantes. Normalmente, si se opera un cambio léxico bien de la base, bien de su extensión en el caso de los términos poliléxicos, estaríamos ante sinonimia. Las alteraciones gráficas, morfosintácticas o morfológicas en una misma unidad serían variantes. Como puede verse, su idea de variante y, sobre todo, de sinonimia en Terminología, sería un tanto distinta de la Faulstich. La autora (2002: 129-161) ha estudiado las causas o factores de índole dialectal (variación geográfica, cronológica, social), funcional, discursivo, cognitivo e interlingüístico que podrían dar lugar a la variación denominativa. En cada caso, las causas de la variación quedarían restringidas a unos tipos diferentes. Así, por ejemplo, la variación dialectal tendría lugar entre textos diferentes de autores diferentes; la variación funcional únicamente podría darse entre textos diferentes de un mismo autor; las causas discursivas quedarían circunscritas a un único texto, y las causas cognitivas en cualquiera de estas combinaciones, puesto que se entremezclarían con el resto de las causas en un plano de actuación diferente.

Creo que estos modelos podrían ser de utilidad, como punto de partida, a la hora de hablar de la variación fraseológica en los textos de especialidad, en combinación con algunos modelos aplicados a la lengua general. Veásmolo a través de los textos jurídicos.

10 A lo que Faulstich (1998) se refiere es que una variante temporal, por ejemplo, podría mostrar también variación lingüística gráfica o morfosintáctica, etc. 


\section{La variación topolectal de la fraseolo- gía jurídica}

Como ya apuntaba en el apartado introductorio, ya me he dedicado, aunque no de forma sistemática, a la variación de la fraseología jurídica motivada por factores dialectales, en concreto, geográficos. Así, en Pastor Lara y Tabares Plasencia (2012), se analizaba la variación expresiva de determinados conceptos en los códigos penales hispánicos. En esta ocasión me he centrado en un corpus de textos judiciales igualmente hispánicos que ahora pasaré a describir.

\subsection{Descripción del corpus}

Atendiendo a los criterios de descripción de corpus de Cabré (2007), el corpus con el que he trabajado es un corpus monolingüe, unidisciplinar (dominio del Derecho procesal penal) y de dimensión disciplinar parcial (Derecho procesal y Derecho penal), que incluye textos escritos de un solo nivel de especialización (elevado) y de un solo género (sentencias judiciales). Para este estudio - como primer paso para un trabajo posterior, mucho más amplio, que abarque todos los países de la América hispana-, me he servido de sentencias pronunciadas por las cortes o los tribunales supremos de Costa Rica, España, Panamá y Uruguay. Estas resuelven recursos de casación penal de resoluciones de tribunales inferiores que han conocido de delitos contra la vida o integridad física (homicidio, asesinato o lesiones), es decir, a la hora de seleccionar los textos, se ha intentado que fueran lo más comparables posible. En total, se han analizado ciento veinte páginas: una media de seis páginas por sentencia, siendo que, por cada país, se han seleccionado cinco resoluciones. El número total de palabras es ca. 84000. Los textos abarcan un período temporal de 5 años, esto es, desde 2009 hasta 2014.

La extracción de las unidades que se analizan se ha llevado a cabo manualmente, puesto que no me interesaba, prima facie, el criterio cuantitativo, amén de que para la extracción de algunas de las UFED no colocacionales hubiera sido muy difícil el empleo de métodos o herramientas de extracción automática. No obstante, he empleado la ayuda de la herramienta de Lista de palabras del programa de concordancias WordSmith Tools. Estas listas me han servido para determinar qué unidades eran comunes o generales frente a otras variantes con la misma designación y/o sentido textual. Manualmente, cuando se presenten los ejemplos textuales se empleará la abreviatura St. (sentencia) más el código del país, según la norma ISO 3166-1 alfa-2.

\subsection{Variación en las sentencias penales hispánicas}

Lo primero que debo decir es que las unidades se han aislado aplicando el modelo clasificatorio elaborado en Tabares Plasencia (2012) y que ya se ha presentado supra. Por lo demás, ya se ha validado recientemente en un corpus de contratos españoles y alemanes de compraventa de inmuebles en un trabajo de esta misma autora en colaboración (Tabares Plasencia y Batista Rodríguez, 2014) y en un corpus de contratos de trabajo también españoles y alemanes (Ivanova y González de León, 2014). Así pues, en los textos judiciales que se han examinado podemos encontrar ejemplos de los tres grandes tipos de UFED mencionadas. Serían todas ellas, en palabras de Faulstich, variantes concurrentes formales de registro (variantes geográficas), es decir, se emplearían para expresar los mismos contenidos semánticos y/o pragmáticos.

1) Cadenas gramaticales con valor preposicional y fórmulas adverbiales. Solo se van a tratar dos ejemplos por cuestiones de espacio. Para referirse al 'delito intentado' o a 'la tentativa de delito’ se constatan las siguientes formas:

En estado de tentativa.

(1) "En consecuencia, se revoca la sentencia, únicamente respecto de la calificación jurídica de concurso material entre un delito de homicidio 
simple en estado de tentativa ${ }^{11}$ y otro consumado, así como, parcialmente, en cuanto a la pena impuesta" (St. - CR).

\section{En grado de tentativa.}

(2) "[...] y como autores del delito de homicidio en grado de tentativa en perjuicio de Carlos Enrique Ramírez Espinosa, imponiéndoles la pena de dieciséis (16) años de prisión" (St. - PA).

La forma habitual en todos los textos, salvo en los de Costa Rica, es en grado de tentativa. En este caso, estamos ante un cambio léxico, con lo que estaríamos ante una variante formal léxica. En los textos costarricenses se alterna igualmente la forma en estado de tentativa con la forma reducida sintácticamente en tentativa:

(3) "Todos y cada uno de estos testigos, como se aprecia de folio 213 a folio 217 vuelto, narraron las circunstancias que rodearon lo hechos en general, y en particular, la manera específica en que el acusado ejecutó las acciones ilícitas finalmente calificadas como un homicidio simple y tres homicidios en tentativa".

En el siguiente caso, para expresar 'sin discrepancia' para tomar una decisión judicial, nos encontramos con variantes concurrentes geográficas donde también puede notarse el cambio sintáctico o morfosintáctico:

(4) "[...] el Tribunal acuerda en forma unánime declarar a R autor responsable de UN DELITO de HOMICIDIO SIMPLE cometido en perjuicio de A y TRES DELITOS de HOMICIDIO SIMPLE" (St. - CR).

(5) "La Suprema Corte de Justicia, por unanimidad y en coincidencia con el Sr. Fiscal de Corte, entiende que corresponde desestimar el recurso de casación interpuesto por el encausado AA, en virtud de que los agravios invocados en sustento de la impugnación no resultan de recibo" (St. - UY).

(6) "El Jurado fue oportunamente interrogado sobre si el abuso de bebidas alcohólicas o estupefacientes, unido a padecer Landelino un trastorno inespecífico de la personalidad, con rasgos de una personalidad narcisista y antisocial, disminuían de forma importante los frenos inhibitorios del acusado, o alternativamente, de forma leve, que dieron lugar a las preguntas $7^{\mathrm{a}}$ y $8^{\mathrm{a}}$ del objeto del veredicto, las cuales fueron respondidas de forma negativa por el colegio popular de forma unánime, [...]" (St. - ES).

2) Construcciones verbonominales. Lo primero que se debe comentar en este apartado es que en los textos analizados se registran sin variación muchas construcciones verbonominales de gran importancia para el género textual y la temática ante la que nos encontramos. Por ejemplo, se hallan abundantes muestras de dictar/ pronunciar sentencia, interponer recurso, imponer la/una pena o impugnar la/una resolución, entre otras. Se constata, asimismo, bastante variación en un mismo texto (la llamada variación funcional de Freixa), es decir, expresiones donde varía algún elemento para evitar la repetición continuada de la misma construcción por motivos estilísticos. Así, el núcleo terminológico de la construcción se sustituye por un hipónimo o por un hiperónimo, del tipo dictar sentencia o dictar resolución donde resolución sería el hiperónimo y sentencia el hipónimo, o, por el contrario, es el nucleo verbal el que se sustituye. Esa motivación estilística hace que aparezcan nuevas combinaciones que no encontramos en todos los textos. Es el supuesto, por ejemplo, de proferir o emitir sentencia/fallo (con el mismo sentido que pronunciar y dictar sentencia, esto es, 'dar a conocer el fallo'), constatable en los textos de Panamá y de Uruguay y que no se registran en los textos de España y Costa Rica analizados.

(7) "La licenciada Nidia Herrera de Leandro, defensora de oficio, ha presentado recurso de Casación en el Fondo contra la sentencia 7 de agosto de 2008, proferida por el Tribunal Superior de la Niñez y Adolescencia que confirmó en todas sus partes, la Sentencia No.08 de 17 de marzo de 2008, proferida por el Juzgado Segundo Penal de Adolescentes del Primer Circuito Judicial de Panamá, [...]." (St. - PA)

(8) "Considera la casacionista que el fallo proferido en segunda instancia contiene errores en cuanto a la sanción impuesta no corresponda a la responsabilidad del imputado, constituyendo esta 
causal, la razón de ser del recurso de casación" (St. - PA)

(9) "En cuanto a la calificación delictual y el grado de participación, la Sala realiza citas doctrinarias y jurisprudenciales que no se compadecen con la presente causa y el cuadro probatorio integrado al proceso, por lo que se configura la violación del principio de congruencia, entre los fundamentos aducidos en la Sentencia recurrida y el respectivo fallo que se emite, configurándose otro error "in iudicando" (petición de principios) susceptible de casación en el fondo" (St. - UY)

Lo mismo ocurre con habilitar un fallo que se registra en Uruguay y que no se halla en el resto de los textos con el sentido de 'fundamentar un pronunciamiento judicial', que vemos en los textos españoles como fundar un fallo:

(10) "En la atacada el Tribunal se apoya en indicios y no en la prueba acreditada en autos, cuando la tipología del derecho represivo uruguayo requiere la plena prueba para habilitar un fallo de condena, pues de lo contrario se estaría afectando una de las principales garantías que establece nuestra Constitución, que es el derecho a la Libertad (artículo 10 de la Carta)" (St. - UY).

(11) “1.-Por la vía especial del artículo 5, número 4 de la Ley Orgánica del Poder Judicial, se denuncia la infracción del derecho fundamental a la presunción de inocencia, consagrado en el artículo 24 párrafo 2 de la Constitución, por no existir una actividad probatoria mínima de cargo en que fundar un fallo condenatorio a sus representados" (St. - ES).

El último ejemplo que propondré es el de conferir traslado (Uruguay) / correr traslado (Costa Rica) / dar traslado (España) que se emplea con el sentido de 'hacer llegar al órgano o parte interviniente en un proceso judicial de las actuaciones Ilevadas a cabo'. En este caso, en todos los textos aparece un núcleo verbal distinto.

(12) "En esta fase de preparación del juicio oral, el art. 790 ( 1 y 2) ordena dar traslado de las diligencias previas al $M^{\circ}$ Fiscal y a las acusaciones personadas, para que, en el plazo común de 5 días, soliciten la apertura del juicio oral formulando escrito de acusación o el sobreseguimiento de la causa o, excepcionalmente, la práctica de diligencias complementarias en el caso de imposibilidad de formular escrito de acusación por falta de elementos esenciales para la tipificación de los hechos" (St. - ES).

(13) "Por Interlocutoria No. 2012, del 29 de agosto de 2012, se dispuso dar ingreso al recurso y se confirió traslado por el término legal (fs. 1360)" (St. UY).

(14) "Admitido el recurso de casación y en cumplimiento de las ritualidades procesales que corresponde a este medio extraordinario de impugnación, se corrió traslado al Procurador General de la Nación y con posterioridad se celebró la audiencia oral prevista en el artículo 2442 del Código Judicial, por encontrarse este negocio en estado de resolver a ello se procede" (St. - CR).

Interesantes son igualmente las transformaciones a que dan lugar estas construcciones verbonominales, esto es, presentan modificaciones tanto sintagmáticas como paradigmáticas, sin por ello dejar de ser la misma unidad fraseológica: así, por ejemplo, proferir sentencia puede dar lugar a proferimiento de sentencia, pero puede ser que esta nominalización - como es el casono se dé en un género textual concreto. Precisamente, son las restricciones de transformación las que más problemas crean a los que aprenden una lengua de especialidad o a los que deben traducir textos especializados a los diferentes ordenamientos hispánicos, ya que, en principio, todas las transformaciones son posibles, pero no todas se verifican (Tabares Plasencia y Pérez Vigaray, 2007: 571). Así, en el caso anterior, la nominalización proferimiento no se verifica. De esta misma manera, pueden constatarse o no, a partir de esas formaciones, determinados nomina agentis. En los textos americanos, por ejemplo, se constatan interesantes nomina agentis a partir de muchas construcciones que no se dan en los textos españoles. Pero este es un tema que desarrollaré en otra ocasión.

3) Textos formularios. En este apartado me referiré solamente al marco de introducción del 
fallo en caso de desestimación del recurso de casación. En este sentido, encontramos bastante variación de la tradición en las prácticas lingüísticas judiciales:

(15) "FALLO

Que debemos declarar y declaramos NO HABER LUGAR al recurso de casación interpuesto por [persona X] contra la sentencia dictada por [Tribunal Y] con fecha de [fecha concreta] que le condenó por [delito concreto. Con expresa imposición de las costas derivadas de sus respectivos recursos de casación. Comuníquese dicha resolución al mencionado [Tribunal Y], con devolución de la causa en su día remitida" (St. - ES)

(16) "Se declara sin lugar [en todos sus extremos] el recurso de casación incoado por la defensa técnica del encartado. La sentencia recurrida se mantiene incólume. Notifíquese” (St. - CR).

(17) “PARTE RESOLUTIVA

En mérito de lo expuesto, la CORTE SUPREMA, SALA DELO PENAL, administrando justicia en nombre de la República y por autoridad de la ley, NO CASA, la Sentencia X de [fecha concreta], emitida por [Tribunal Y], por medio de la cual se CONFIRMA la resolución calendada [fecha concreta], proferida por [Tribunal M] de la Provincia de Panamá

Notifíquese" (St. - PA).

(18) "En mérito a las consideraciones precedentes, a lo dispuesto por los artículos 269 y concordantes del Código del Proceso Penal y demás normas citadas, la Suprema Corte de Justicia, por unanimidad,

FALLA:

DESESTIMASE EL RECURSO DE CASACION INTERPUESTO, DECLARANDOSE DE OFICIO LAS COSTAS CAUSADAS.

OPORTUNAMENTE, DEVUELVASE" (St. UY).

\section{Conclusión}

Me hubiera gustado poder ofrecer más ejemplos, y no solamente la variación de unas determinadas unidades, sino también de su comportamiento en los textos trabajados, pero, desgraciadamente, no dispongo de más espacio para ello. Desde un punto de vista traducto- lógico es interesante tener en cuenta todas las transformaciones posibles y constatables en los textos de una UFE y comprobar si también es posible verificar variaciones motivadas por factores dialectales en estas transformaciones, pues, como ya he dicho, realmente son las restricciones de transformación las que más problemas crean a la hora de producir textos especializados. Por lo demás, mi intención ha sido mostrar cómo el modelo clasificatorio elaborado en 2012 también es apropiado para este género textual y que algunos modelos de variación terminológica son practicables para llevar a cabo una sistematización de la variación fraseológica. Por el momento, este ha sido un ensayo, que debería mejorarse en el futuro, en el sentido de ofrecer una sistematización de la variación que se presenta en los textos. Mi intención es seguir indagando en esta línea de investigación, ampliar el corpus de análisis, no solo con textos de este mismo género del resto de países cuyo Derecho se vehicula a través del español, sino con textos en lengua alemana, con el fin de elaborar una herramienta útil para traductores de la combinación lingüística alemán-español.

\section{Bibliografía citada}

Bevilacqua, Cleci Regina, 1996: A Fraseologia Jurídico-Ambiental. Tesis de maestría, Universidade Federal do Rio Grande do Sul, Porto Alegre.

Bevilacqua, Cleci Regina, 1996: "Do domínio jurídico-ambiental: proposta de critérios para seleção e tratamento de unidades fraseológicas" en Actas del V Simposio Iberoamericano de Terminología: Terminología, Ciencia y Tecnología. México (1996) [http://www.ufrgs.br/riterm/esp/simposios_anteriores_1996.html, fecha de consulta: 15 de septiembre de 2014].

Bevilacqua, Cleci Regina, 2004: Unidades fraseológicas eventivas: descripción y reglas de formación en el ámbito de la energía solar. Tesis doctoral, Universitat Pompeu Fabra de Barcelona [http://tdx.cat/bitstream/handle/10803/7515/ tcrb.pdf?sequence $=1$, fecha de consulta: 15 de septiembre de 2014]. 
CoRPAs, Gloria, 1996: Manual de fraseología española, Madrid: Gredos.

Cabré, $M^{a}$. Teresa, Rosa Estopá y Mercè LoRente, 1996: "Terminología y fraseología” en Actas del V Simposio Iberoamericano de Terminología: Terminología, Ciencia y Tecnología. México [http://www. ufrgs.br/riterm/esp/simposios_anteriores_1996. html, fecha de consulta: 30 de septiembre de 2014]

Cabré, Ma Teresa, 2002: "Textos especializados y unidades de conocimiento: metodología tipologización" en Joaquín García Palacios y $\mathrm{M}^{\mathrm{a}}$ Teresa Fuentes (eds.): Texto, terminología y traducción, Salamanca: Ediciones Almar, 15-36.

CABRÉ, Ma Teresa, 2005: "Recursos lingüísticos en la enseñanza de lenguas de especialidad" en Josefina Ómez De Enterría (coord.): V Jornada- Coloquio de la Asociación Española de Terminología AETER, Universidad de Alcalá de Henares (2004). [http://cvc.cervantes.es/obref/aeter/conferencias/cabre.htm, fecha de consulta: 15 de noviembre de 2014].

CABré, Ma Teresa, 2007: "Constituir un corpus de textos de especialidad: condiciones y posibilidades" en Michel Ballard y Carmen Pineira-TresmonTANT (eds.): Les corpus en linguistique et en traductologie, Arras: Artois Presses Université, 89-106 [http://exordio.qfb.umich.mx/archivos\%20 pdf\%20de\%2otrabajo\%2oumsnh/aphilosofia/ca07arra.pdf, fecha de consulta: 15 octubre 2014].

Dobrovol'skiJ, Dmitrij, 1988: Phraseologie als Objekt der Universalienlinguistik, Leipzig: Verlag Enzyklopädie.

Echenique Elizondo, María Teresa, 2003: "Pautas para el estudio histórico de las unidades fraseológicas" en José Luis Girón Alconchel y otros (coords.): Estudios ofrecidos al profesor José Jesús de Bustos Tovar, vol. I, Madrid: Servicio de Publicaciones de la Universidad Complutense de Madrid, 545-560

Faulstich, Enilde, 1995: Base metodológica para pesquisa em socioterminologia. Termo e va- riaçao, Brasília: Universidade de Brasília.

FAULSTICH, Enilde, 1997: "Variaçoes terminológicas: princípios lingüísticos de análise e método de recolha" [http://lilla2.unice.fr/labo_fr/Coll\&Ouv/ Colloques/terminog6/enilde.htm, fecha de consulta: 13 de octubre de 2014].

FAULSTICH, Enilde, 1998: "Entre a sincronia e a diacronia: variação terminológica no código e na língua, en Actas del VI Simposio Iberoamericano de Terminología: Terminología, desarrollo e identidad nacional (La Habana, 16-19 de noviembre de 1998). [http://www.ufrgs.br/riterm/esp/simposios_anteriores_1998.html, fecha de última consulta: 11 de noviembre de 2014].

FAULSTICH, Enilde, 2000: "Principes formels et fonctionnels de la variation en terminologie", Terminology: International Journal of theoretical and applied issues in specialized communication 5 (1), 93-106.

FAULSTICH, Enilde, 2002: "Variação em terminologia. Aspectos de socioterminologia" en Gloria GuerRero Ramos y Manuel Fernando Pérez Lagos (coords.): Panorama actual de la terminología, Granada: Comares, 65-91.

Feldekircher Müller, Alexandra y Cleci Regina BeviLACQUA, 2010: "As fraseologias das Sentenças Jurídicas do Direito Previdenciário", Calidoscópio 8 (3), $234-240$.

Freixa, Judit, 2002: La variació terminològica. Anàlisi de la variació denominativa en textos de diferent grau d'especialització de l'àrea de medi ambient. Tesis doctoral, Universitat de Barcelona [http://www.tesisenxarxa.net/TESIS_UB/AVAILABLE/TDX-0313103-110156//TesiJF.pdf, fecha de consulta: 24 de septiembre de 2014].

Garcia-Page, Mario, 1996: "Sobre las variantes fraseológicas en español", Revista canadiense de estudios hispánicos XX (3), 477-489.

García-Page, Mario, 1999: "Variantes morfológicas y unidades fraseológicas”, Paremia 8, 225-230.

García Valle, Adela, 2006: "Una primera aproximación al estudio de la formulación jurídica notarial de la Edad Media desde la perspectiva de la 
fraseología” en José Luis Girón Alconchel y otros (coords.): Estudios ofrecidos al profesor José Jesús de Bustos Tovar, vol. II, Madrid: Arco/Libros, 1385-1400.

García Valle, Adela, 2008: "A propósito de la importancia de las locuciones adverbiales en el análisis de los textos medievales: algunas notas para la edición de textos jurídicos antiguos" en Inés Olza Moreno, Manuel Casado Velarde y Ramón GonZález RuIz (coords.): Actas del XXXVII Simposio Internacional de la Sociedad Española de Lingüística, Pamplona: Universidad de Navarra, 195-206. García Valle, Adela, 2010: "Locuciones adverbiales de ámbito jurídico: de los fueros medievales a su consolidación en la lengua", Revista de Filología Española (RFE) XC (1), 99-134.

García Valle, Adela y Amparo Ricós Vidal, 2007: "Estudio filológico comparativo de documentación peninsular medieval. Las fórmulas jurídicas desde la fraseología" en David Trotter (ed.): Actes du XXIVe Congrès International de Linguistique et de Philologie Romanes, Tübingen: Niemeyer, 173186.

GLÄSER, Rosemarie, 2007: "Fachphraseologie" en Harald Burger (ed.): Phraseologie: ein internationales Handbuch zeitgenössischer Forschung/ Phraseology: a international Handbook of contemporary research, Berlin: Walter de Gruyter, 482-505.

Gouadec, Daniel, 1994: "Nature et traitement des entités phraséologiques. Terminologie et phraséologie. Acteurs et amenageurs" en Actes du deuxième Université d'Automne en Terminologie, Paris: La Maison du Dictionnaire, 164-193.

Gülich, Elisabeth y Ulrich Krafft, 1998: "Zur Rolle des Vorgeformten in Textproduktionsprozessen" en Jan Wirrer (ed.): Phraseologismen. Text und Kontext, Bielefeld: Aisthesis, 11-32.

KJAER, Anne Lise, 1991: "Phraseologische Wortverbindungen in der Rechtssprache?" en Christine PALM (ed.): EUROPHRAS 90. Akten der internationalen Tagung zur germanistischen Phraseolo- gieforschung, Uppsala: Deutsches Institut der Universität Uppsala, 115-122.

KJAER, Anne Lise, 1994: "Zur kontrastiven Analyse von Nominationsstereotypen der Rechtssprache deutsch-dänisch" en Barbara SANDIG (ed.): EUROPHRAS 92. Tendenzen der Phraseologieforschung, Bochum: Brockmeyer, 317-348.

KJAER, Anne Lise, 2007: "Phrasemes in legal texts" en Harald Burger (ed.): Phraseologie: ein internationales Handbuch zeitgenössischer Forschung/ Phraseology: a international Handbook of contemporary research, Berlin: Walter de Gruyter, 506-516.

KoIKe, Kazumi, 2001: "Variación fraseológica del español”, Varilex 9 [http://lingua.cc.sophia.ac.jp/ varilex/index.php, fecha de consulta: 13 de diciembre de 2014].

KoIKE, Kazumi, 2003: "Las unidades fraseológicas del español: su distribución geográfica y variantes diatópicas", Epos XIX, 47-65.

Krüger, Elke y Encarnación Tabares Plasencia, 2008: "¿Qué es una necesidad? Reflexiones acerca de una microfunción y sus formas de realización en contratos de trabajo españoles y alemanes" en Encarnación Tabares Plasencia, Vessela Ivanova y Elke Krüger (eds.): Análisis lingüístico contrastivo de textos especializados en español y alemán, Berlin: Frank \& Timme, 105-126

Ivanova, Vessela y María Gonzalez De León, 2014: "Phraseologie und Fachlexik in deutschen und spanischen Arbeitsverträgen. Ergebnisse einer computergestützten kontrastiven Korpusanalyse" en Encarnación Tabares Plasencia (ed.): Fraseología jurídica contrastiva español-alemán/Kontrastive Fachphraseologie der spanischen und deutschen Rechtssprache, Berlin: Frank \& Timme, 35-78.

Montoro Del Arco, Esteban, 2004: "La variación fraseológica y el diccionario" en Paz Battaner y Janet DeCESARIS (eds.): De Lexicografia (Actes del I Symposium Internacional de Lexicografia), Barcelona: Institut Universitari de Lingüística Aplicada, 591-604. 
Ortega Ojeda, Gonzalo y María Isabel González Aguilar, 2005: "En torno a la variación de las unidades fraseológicas" en Ramón Almela, EstanisIao Ramón Trives y Gerd Wotjak (eds.): Fraseología Contrastiva. Con ejemplos tomados del alemán, español, francés e italiano, Murcia: Universidad de Murcia.

Pastor Lara, Alejandro y Encarnación Tabares PlaSENCIA, 2012: "Estudio de la variación topolectal de las UFE en el ámbito del Derecho Penal español e hispanoamericano" en Antonio Pamies Bertrán, Lucía Luque Nadal y José Manuel Pazos Bretaña (eds.): Phraseology and Discourse: Cross Linguistic and Corpus-Based, Baltmannsweiler (Alemania): Schneider Hohengehren, 355-366.

Tabares Plasencia, Encarnación, 2010: "Ausgewählte Übersetzungsprobleme der juristischen $\mathrm{Fa}$ chphraseologie. Vergleich Deutsch-Spanisch" en Jarmo Korhonen y otros (eds.): Phraseologie: global - areal - regional, Tübingen: Narr.

TABARes Plasencia, Encarnación, 2012: "Analyse und Abgrenzung rechtssprachlicher phraseologischer Einheiten im Spanischen und Deutschen und ihre Bedeutung für die Übersetzung”, Lebende Sprachen 57 (2), 314-328.

Tabares Plasencia, Encarnación (ed.), 2014: Fraseología jurídica contrastiva español-alemán/Kontrastive Fachphraseologie der spanischen und deutschen Rechtssprache, Berlin: Frank \& Timme.

Tabares Plasencia, Encarnación y José Juan Batista Rodriguez, 2014: "Unidades fraseológicas especializadas en los contratos de compraventa de inmuebles españoles y alemanes" en Encarnación Tabares Plasencia (ed.): Fraseología jurídica contrastiva español-alemán/Kontrastive Fachphraseologie der spanischen und deutschen Rechtssprache, Berlin: Frank \& Timme, 97-147.

Tabares Plasencia, Encarnación y Juan Manuel Pérez VigaraY, 2007: "Fraseología terminológica: estado de la cuestión y ejemplo de análisis contrastivo", Revista de Filología de la Universidad de La Laguna (RFULL) 25, 567-577.
Tercedor Sanchez, Maribel, 1999: "La fraseología en el lenguaje biomédico: análisis desde las necesidades del traductor" en Estudios de Lingüística del Español 6 [http://elies.rediris.es/elies.html, fecha de consulta: 3 de diciembre de 2014].

Zuluaga, Alberto, 1980: Introducción al estudio de las expresiones fijas, Tübingen: Max Hueber verlag. 